\title{
Chronic consumption of three forms of palm oil diets alters glomerular filtration rate and renal plasma flow
}

\author{
Favour N. Beshel, Atim B. Antai and Eme E. Osim \\ Department of Physiology, Faculty of Basic Medical Sciences, University of Calabar, Calabar, Nigeria
}

\begin{abstract}
The effects of chronic consumption of three types of palm oil diets on glomerular filtration rate (GFR), renal plasma flow (RPF) and blood pressure were studied. Wistar rats were randomly assigned into four groups of ten rats each respectively; control, fresh (FPO), photoxidized (PPO), thermoxidized (TPO) palm oil diet-fed rats. The control group was fed rat chow only, while experimental groups had different palm oil diets at $15 \% \mathrm{wt} / \mathrm{wt}$ for twelve weeks and tap water ad libitum. After the feeding period, GFR, RPF, systolic (SBP) and diastolic (DBP) blood pressures were measured. GFR and $\mathrm{RPF}$ of the TPO $(0.07 \pm 0.01 \mathrm{ml} / \mathrm{min}$ and $1.50 \pm 0.24 \mathrm{ml} / \mathrm{min})$ and $\mathrm{PPO}(0.14 \pm 0.01$ and $2.54 \pm 0.11)$ groups were significantly $(p<0.001)$ reduced compared with control $(0.77 \pm 0.04$ and $5.3 \pm 0.30)$ and FPO $(0.81 \pm 0.02$ and $4.8 \pm 0.13)$ groups. The GFR and RPF of the TPO group was significantly $(p<0.05)$ higher than that of the PPO group. SBP and DBP of the TPO group $(140 \pm 3 \mathrm{mmHg}$ and $106 \pm 4 \mathrm{mmHg})$ were significantly $(p<0.01)$ increased when compared with the control $(112 \pm 6.4$ and $78 \pm 5)$, FPO (118 \pm 5 and $81 \pm 6)$ and PPO (122 \pm 5 and $89 \pm 5)$ groups. These results suggest that chronic consumption of TPO and PPO caused a decrease in GFR and RPF, but increased blood pressure in rats, while FPO did not adversely affect blood pressure, GFR and RPF.
\end{abstract}

Key words: Blood pressure - Glomerular filtration rate - Palm oil — Renal plasma flow — Photooxidation

Abbreviations: GFR, glomerular filtration rate; RPF, renal plasma flow; FPO, fresh palm oil; PPO, photoxidized palm oil; TPO thermoxidized palm oil; SBP, systolic blood pressure; DBP, diastolic blood pressure; ROS, reactive oxygen species; PAH, para-amino hippuric acid; HMF, 5-hydroxymethyl-2furaldehyde; TRF, tocotrienols rich fraction.

\section{Introduction}

Palm oil is the most widely produced vegetable oil consumed as cooking oil (fresh and thermoxidized) in most parts of Africa especially in Nigeria (Osim et al. 1994; Ebong et al. 1999). The nutritional and health attributes of palm oil have been well documented especially when eaten in its fresh form. Fresh palm oil is the largest natural source of tocotrienol (Mukherjee and Mitra 2009). It is also rich in carotenoids; actually it is the richest source of carotenoids (about 15 times more than carrots and 300 times more than

Correspondence to: Favour N. Beshel, Department of Physiology, Faculty of Basic Medical Sciences, College of Medical Sciences, University of Calabar, Calabar 540001, Nigeria

E-mail: favourbeshel@unical.edu.ng tomatoes) (Mukherjee and Mitra 2009). Tocotrienol and carotenoids play an important role by acting as antioxidants, protecting cells and tissues from the damaging effects of free radicals. However, a lot of the so called 'fresh palm oil' sold in Nigerian markets is not fresh as shown by their peroxide value (Moh et al. 1999; Egbe et al. 2003; Adnan et al. 2009). Much of the oil is exposed to sunlight and is therefore photoxidized. Moreover, some may be autoxidized even without exposure. The photoxidized and autoxidized palm oil are some common forms of the oil erroneously called fresh palm oil. The other form of palm oil is thermoxidized palm oil which has undergone several rounds of heating.

Oxidized state of palm oil poses potential dangers to the physiological and biochemical functions of the body (Ebong et al. 1999). Oxidized palm oil produces an adverse effect on the plasma lipid profile, free fatty acids 
and cerebrosides (Ebong et al. 1999; Mukherjee and Mitra 2009). Available evidence suggests that, at least part, of the oxidized palm oil's effect on health is due to the generation of toxicants (free radicals), reactive oxygen species (ROS) especially. Recent studies have also shown that consumption of oxidized unsaturated fatty acids may contribute to the pathogenesis of atherosclerosis by increasing lipid peroxidation and total cholesterol levels (Adam et al. 2008). The kidneys are the major organs responsible for the excretion of waste products from the blood as well as for blood pressure regulation (Guyton and Hall 2001). However, this organ is very susceptible to oxidative stress which results from an imbalance between reactive oxygen species and defence mechanisms. This may lead to tissue inflammation and damage (Martin and Goeddeke-Merickel 2005). The presence of inflammation is well documented factor influencing the development of oxidative stress in dialysis patients (Samouilidou et al. 2003). Oxidative stress can cause hypertension and vice-versa (Vaziri 2004). Therefore, hypertension, oxidative stress and inflammation are closely related and contribute to a viscious cycle that can lead to a progressive deterioration of hypertension and target organ dysfunction, such as the heart and kidneys (Vaziri 2004). The effects of chronic consumption of thermoxidized and photoxidized palm oil diets on renal function have not been previously ascertained. If indeed thermoxidized palm oil is harmful to tissues, to what extent is this harm? Is it enough to cause significant changes in the function of the kidneys? If so, what significant changes does it make, especially concerning the function of the kidneys and their role in filtration and blood pressure? This study therefore aims at finding out the effects of chronic consumption of these two forms of palm oil diets on the kidney function.

\section{Materials and Methods}

\section{Experimental animals}

Forty Wistar albino rats each weighing between 140-160 g at the beginning of the experiment were randomly assigned to four groups of ten each, respectively: Control (fed normal rat chow), fresh Palm oil group (FPO; fed 15\% w/w fresh palm oil), photoxidized palm oil group (PPO; fed 15\% w/w photoxidized palm oil diet) and thermoxidized palm oil group (TPO; fed 15\% w/w thermoxidized palm oil diet). The palm oil diets were scheduled according to Osim et al. (1994) and Owu et al. (1998). Briefly, eighty five grams of rat chow was mixed with fifteen grams of fresh, thermoxidized or photoxidized palm oil which is the usual composition of a typical Black African diet. The two oxidized forms of palm oil were prepared using the methods of Owu et al. (1998) and Raza et al. (2009). The peroxidation numbers of the TPO and PPO were 5.16 and 3.48, respectively. The peroxide values were determined using the standard AOCS method (AOCS 1989). The animals were fed with their separate diets for 12 weeks. For each animal free access to water was allowed and it was kept in a separate metabolic cage throughout the duration of the experiment. The research was conducted in accordance with internationally accepted principles for laboratory animal use described in the European community guidelines.

\section{Renal clearance studies}

After anaesthesizing the animal intraperitoneally with a mixture of $1 \%(\mathrm{w} / \mathrm{v})$ alpha chloralose and $25 \%(\mathrm{w} / \mathrm{v})$ urethane in normal saline at a dose of $5 \mathrm{ml} / \mathrm{kg}$ body weight, the right femoral vein was cannulated for infusion of inulin and paramino hippuric acid. A priming dose of inulin (16 mg/kg body weight) and paramino-hippuric acid (PAH) ( $8 \mathrm{mg} / \mathrm{kg}$ body weight) were given to the animals with the use of a syringe, after which the cannula was connected to an infusion pump (11plus, Havard apparatus, Holliston MA, USA) for the infusion of sterile normal saline solution containing inulin $(36 \mathrm{mg} / \mathrm{ml})$ and para-amino hippuric acid $(\mathrm{PAH})(5.8 \mathrm{mg} / \mathrm{ml})$, (Gabel et al. 1996; Fisher et al. 2000) at a rate of $0.06 \mathrm{ml} / \mathrm{min}$. Through a small lower abdominal incision, the urinary bladder was cannulated with a short self retaining catheter (pp100, polythene tubing). The urethra was ligated to avoid voiding of urine.

After the equilibration period (a period within which three 20 min urine collections yielded constant or the same volume) of 60 mins, urine samples were collected in preweighed vials for another $60 \mathrm{~min}$ period. The urine samples were thereafter stored in a freezer until when required. Terminal blood samples were collected from the left femoral vein into heparinized tubes and blood plasma was immediately separated by centrifugation $(3000 \times g$ for $10 \mathrm{~min})$. Separated plasma was put into Eppendorf tubes and stored in a freezer until when required.

Simulteneous determination of inulin and P-aminohippuric acid in the plasma and urine by high performance liquid chromatography.

This was done using the method of Baccard et al. (1999). The liquid chromatograph consisted of a model 9012 HPLC pump and a manual rheodyne 7125 valve equiped with a $2 \mu$ l loop. The chromatographic separations were carried out using a $5 \mu$ particle size lichrospher column 100 RP8 $(250 \times 4 \mathrm{~mm}$ id, agilent technologies, Germany) and a spectroflow 785 UV detector. The mobile phase consisted of acetonitrile E chromosolv (Sigma-Aldrich) in $0.01 \mathrm{~mol} / 1$ potassium dihydrogen phosphate (BDH chemicals Ltd, Poole England), containing 0.02 triethyl amine (TEA) (Alfa Desar) 
and adjusted to $\mathrm{pH} 3.0$ with o-phosphoric acid. The internal standard used was Tannic acid.

\section{Standards and quality controls}

A working solution was prepared by mixing stock solutions of inulin and PAH (50:50, v/v). Working standards were prepared from this solution by serial dilution with distilled water to yield concentrations of $12.2,25,50$, and $100 \mathrm{mg} / \mathrm{l}$ for inulin and 6.25; 12.5, 25 and $50 \mathrm{mg} / \mathrm{l}$ for PAH.

\section{Sample preparation}

Aliquots (200 ml) of standards, test plasma and urine samples were diluted at the ratio of $1: 2$ for PAH and 1:5 for inulin with distilled water. These were transferred into clean conical tubes (SGE France Sarl, Villeneuve-saint- George, France). Into each tube $50 \mu$ lof the internal standard (Tannic acid) stock solution and $100 \mu \mathrm{l}$ of perchloric acid (0.7\%) were added. The tubes containing inulin were vortexed briefly, left in boiling water for $60 \mathrm{~min}$ to hydrolyse inulin to fructose and to convert fructose to 5-hydroxymethyl-2-furaldehyde (HMF). Then the samples were cooled in tap water for $5 \mathrm{~min}$. After centrifugation ( $4000 \mathrm{rpm}$ for $5 \mathrm{~min}$ ) $20 \mu \mathrm{l}$ of the clean supernatant were injcted into the HPLC system.

\section{Blood pressure measurements}

The animals were first weighed and anaesthesized with a mixture of $1 \%(\mathrm{w} / \mathrm{v})$ alpha chloralose and $25 \%(\mathrm{w} / \mathrm{v})$ urethane in normal saline at a dose of $5 \mathrm{ml} / \mathrm{kg}$ body weight intraperitoneally. This preparation does not alter resting blood pressure, heart rate and cardiovascular responses for at least 3 hours after anaesthesia (Odigie et al. 2004). A tracheostomy was performed to gaurantee free breathing. A cut was made on the left thigh and muscles carefully teased to expose the femoral vein and artery (lateromedially). The connective tissues joining these vessels were carefully separated with forceps to ensure that none of them was injured. The left femoral artery was isolated and canulated with the use of an intra-arterial cannula (Portex limited, Hythe Kent, England). This cannula was connected to a blood pressure transducer (P23D Statham Hart Rey, Puerto Rico) which was connected to a grass polygraph (Model 7D Grass instruments Co. Quincy Mass, USA) for the recording of blood pressure. From the tracings obtained, the systolic and diastolic blood pressures and heart rates were calculated against timer recordings of the polygraph.

\section{Statistical analysis}

The results were expressed as mean \pm standard error of mean (SEM). The results were analysed using graphPad prism software version 5 (GraphPad Software, SanDiego, CA). One-way analysis of variance (ANOVA) was used to compare means followed by a post hoc Bonferroni test where $p$ values were significant. $p=0.05$ was considered significant.

\section{Results}

The retention time (period within which the HPLC system will distinctly resolve a particular substance and express it as detector signals for PAH, tannic acid (internal standard) and $\mathrm{HMF} /$ inulin were $3.2 \mathrm{~min}, 5.33 \mathrm{~min}$ and $7.25 \mathrm{~min}$, respectively.

Changes in renal plasma flow (RPF) and glomerular filtration rate (GFR)

The RPF and GFR of the thermoxidized and photoxidized palm oil diet groups were significantly $(p<0.001)$ lower than those of the control and FPO diet groups (Figs. 1 and 2).

The mean RPF in photoxidized (PPO) and thermoxidized (TPO) palm oil diet groups were significantly $(p<0.001)$ lower than the control and fresh palm oil (FPO) diet groups, while the mean RPF of TPO group was significantly $(p<0.01)$ different from PPO group (Fig. 1).

There was also a significant $(p<0.001)$ difference in the mean GFR between the groups. The mean GFR in the TPO and PPO groups were significantly $(p<0.001)$ lower than the control and FPO groups. The mean GFR of TPO group was significantly $(p<0.05)$ lower than that of PPO group (Fig. 2).

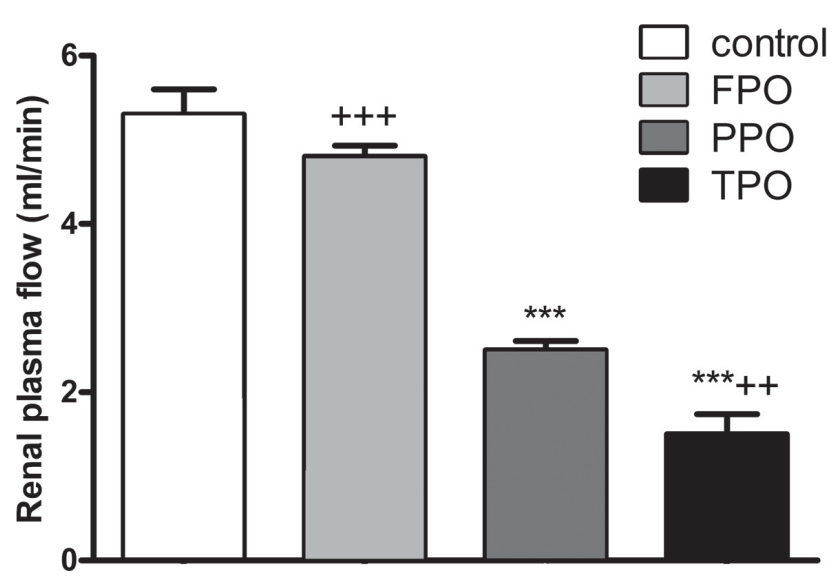

Figure 1. Renal plasma flow $(\mathrm{ml} / \mathrm{min})$ in the control, fresh palm oil (FPO), photoxidized palm oil (PPO) and thermoxidized palm oil (TPO) diet-fed albino rats. Values represent mean \pm SEM. ${ }^{* * *} p<0.001 \mathrm{TPO}$ and PPO vs. control. ${ }^{+++} p<0.001 \mathrm{TPO}$ and PPO vs. FPO; ${ }^{++} p<0.01$ TPO vs. PPO. 
Changes in systolic, diastolic pressures

The systolic and diastolic blood pressures in the control, PPO and TPO groups are shown in Table 1 . There was a significant $(p<0.001)$ difference in the mean systolic blood pressure (SBP) between the groups. The mean SBP of the TPO group was significantly $(p<0.01$ and $p<0.05)$ higher than that of control and FPO groups. However, the mean SBP of PPO was higher than the control even though it was not statistically significant (Table 1).

The mean DBP of TPO was significantly $(p<0.001$; $p<0.05$ ) higher than the control and FPO groups (Table 1). There was no significant difference in DBP when the PPO was compared with FPO and control.

\section{Discussion}

The effects of three forms of palm oil diets on GFR, renal plasma flow, blood pressure of albino rats of the Wistar strain was studied. The results showed that the mean GFR and RPF of PPO and TPO groups were significantly reduced than that of the control group. Interestingly, the GFR and RPF values of the FPO group were comparable with the control values. A study by Odigie et al. (2004) had reported a GFR value of $0.88 \mathrm{ml} / \mathrm{min}$ in normal rats which is consistent with the GFR value in this study. In acute hypertensive states, GFR normally increases (Chou and Marsh 1988) while a decrease in blood pressure would result to a decrease in GFR (Guyton and Hall 2001). In the present study, however, our results showed a decrease in GFR and RPF with an increase in blood pressure. This is in line with a recent study by Bloomfield et al. (2013) which reported that chronic hypertension is significantly associated with a decrease in GFR. It is possible that the reduction in GFR may be a result of injury to the glomerulus. Osim et al. (1994) had already shown that chronic consumption of thermoxidized palm oil destroys kidney tissues. There is evidence that the tocotrienol rich fraction (TRF) of fresh palm oil protects against renal injury (Rajavel et al. 2012; Nowak et al. 2012). Therefore TRF could have contributed to the normal GFR of the fresh palm oil-

Table 1. Systolic and diastolic blood pressures of control, fresh (FPO), photoxidized (PPO) and thermoxidized (TPO) palm oil diet-fed rats

\begin{tabular}{lcrrr}
\hline $\begin{array}{l}\text { Blood } \\
\text { pressure } \\
(\mathrm{mmHg})\end{array}$ & control & FPO & PPO & TPO \\
\hline $\begin{array}{l}\text { Systolic } \\
\text { Diastolic }\end{array}$ & $112 \pm 6$ & $118 \pm 5$ & $122 \pm 5^{* *}$ & $140 \pm 3^{* *+}$ \\
\hline${ }^{* *} p<0.001,{ }^{+} p<0.05$ vs. control and FPO group. &
\end{tabular}

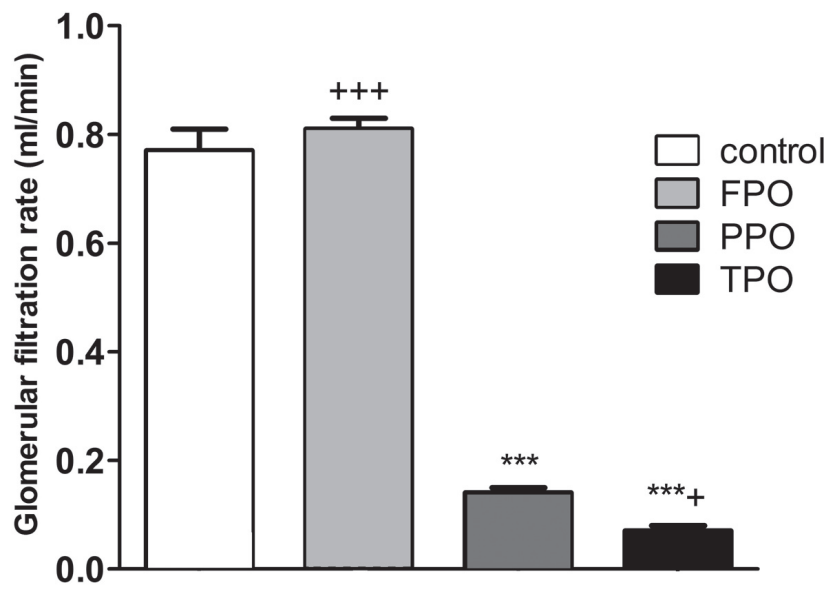

Figure 2. Glomerular filtration rate $(\mathrm{ml} / \mathrm{min})$ in the control, fresh palm oil (FPO), photoxidized palm oil (PPO) and thermoxidized palm oil (TPO) diet-fed rats. ${ }^{* *} p<0.001$ TPO and PPO $v$ s. control; ${ }^{+++} p<0.001 \mathrm{TPO}$ and PPO vs. FPO; ${ }^{+} p<0.05 \mathrm{TPO} v$ s. PPO.

treated group, while the lack of TRF in the TPO and PPO may have contributed to the reduced GFR in these study groups.

The RPF of these animals also followed the same trend. This is indicative of a kidney disease and is in line with what other studies have shown that an extremely low GFR and/or RPF is indicative of a kidney disease (Pfeffer et al. 2003). Also, Adam et al. (2008) reported that chronic consumption of thermally oxidized palm oil could lead to the generation of ROS. These species are known to cause oxidative stress in high concentrations to which the kidneys are highly susceptible (Osim et al. 1994; Martin and Goeddeke-Merickel 2005). As a result of oxidative stress a chronic kidney disease may develop (Ichikawa et al. 1994).

In this study, thermoxidized palm oil caused a significant increase in systolic and diastolic blood pressure. This is in agreement with some previous studies that reported that thermally oxidized palm oil diets caused an increase in blood pressure (Osim et al. 1996; Adam et al. 2008; Ng et al. 2012). The observed results could be attributed to the content of TPO that has a high amount of saturated fatty acids and ROS than fresh and photoxidized palm oil (Leong et al. 2008). Chronic consumption of thermally oxidized palm oil could lead to the generation of reactive oxygen species, causing oxidative damage, thereby predisposing to atherosclerosis (Schnackenberg 2002; Adam et al. 2008). Oxygen-free radicals play well established roles in the pathophysiology of atherosclerosis, chronic kidney disease, diabetes and ischemic reperfusion injury (Knight 1998; Dobashi 2000; Martin and Goeddeke-Merickel 2005).

Photoxidation of palm oil has been known to produce higher peroxide values than FPO (Egbe et al. 2003). In our 
present study, PPO showed a trend of raised blood pressure even though this was not significant. It could be speculated that the degree of peroxidation in PPO was not high enough to cause an increase in blood pressure.

The blood pressure of rats fed with FPO did not show any significant change when compared with control. This shows that fresh palm oil did prevent an increase in blood pressure. This may be because of the fact that fresh palm oil has a very high concentration of tocotrienol, the most potent form of vitamin E and carotenoids which play an important role by acting as antioxidants, protecting cells and tissues from the damaging effects of free radicals (Mukherjee and Mitra 2009). These constuents therefore have beneficial effects on oxidative stress related to hypertension (Narang et al. 2004). Therefore fresh palm oil is beneficial in protecting the cardiovascular system from oxidative stress.

In conclusion, chronic consumption of TPO and PPO caused a decrease in GFR and RPF, but increased blood pressure in rats, while FPO did not adversely affect BP, GFR and RPF.

Acknowledgment. The study was supported by the University of Calabar Post graduate study fellowship award to Dr F. N. Beshel.

There is no conflict of interest.

\section{References}

Adam S. K., Soelaiman I. N., Umar M. N., Muhammed N., Jaarin K. (2008): Effects of repeatedly heated palm oil on serum lipid profile, lipid peroxidation and homocysteine levels in a post menopausal rat model. Mogil J. Med. 11, 145-151

Adnan A., Raza S. A., Qureshi F. M., Asim H., Najaf S., William J. (2009): Analytical investigation of oxidative deterioration of sunflower oil stored under different conditions. EJEAFChe. 8, 1043-1051

AOCS. Official Methods and Reccomended Practices of the American oil. Chemists' Society. 5th edition champaign I. L., 1989, pp. 48-62

Baccard N., Hoizey G., Frances C., Lamiable D., Trenque T., Millart H. (1999): Simultaneous determination of inulin and p-aminohippuric acid (PAH) in human plasma and urine by high performance liquid chromatography. Analyst. 124, 833-836 http://dx.doi.org/10.1039/a902009h

Bloomfield G. S. Yi S. S., Astor B. C., Kramer H., Shea S., Shlipak M. G., Post W. S. (2013): Blood pressure and chronic kidney disease progression in a multi-racial cohort: the multi-ethnic study of atherosclerosis. J. Hum. Hyperten. 27, 421-426 http://dx.doi.org/10.1038/jhh.2013.1

Chou C. L., Marsh D. J. (1988): The course of proximal tubule response to acute hypertension in the rat. Am. J. Physiol. 254, F601-607

Dobashi K., Gosh B., Orak J. K., Singh I., Singh A. K. (2000): Kidney-ischemia reperfusion: modulation of antioxidant defences. Mol. Cell. Biochem. 205, 1-11
http://dx.doi.org/10.1023/A:1007047505107

Ebong P. F., Owu D. U., Isong E. U. (1999): Influence of palm oil (Elaesis guinneensis) on health. Plant Foods Hum. Nutr. 53, 209-222

http://dx.doi.org/10.1023/A:1008089715153

Egbe N. O., Obembe A. O., Inyang S. O., Nneoyi-Egbe A. F. (2003): Palm oil deterioration induced by ionizing radiation. IRPS $17,14-17$

Fisher P. A. Bogoliuk C. B. Ramirez A. J. Sanchez R. A., Masnatta L. D. (2000): A new method for evaluation of renal function without urine collection in rat. Kidney Int. 58, 1336-1341 http://dx.doi.org/10.1046/j.1523-1755.2000.00290.x

Gabel R. A. Ranaei R. A., Kivlighn S. D. (1996): A new method for measuring renal oxidant stress as a unifying concept of cardiovascular disease in uremia. Kidney Int. 60, 358-363

Guyton A. C., Hall J. E. (2001): The kidneys and body fluids. In: Text book of Medical Physiology. (Eds. M. J. Wonsiewicz and R. Hallowell), pp. 884-900, Elsevier Saunder, Philadelphia

Ichikawa I., Kiyama S., Yoshioka T. (1994): Renal anti-oxidant enzymes: their regulation and function. Kidney Int. 45, 1-9 http://dx.doi.org/10.1038/ki.1994.1

Knight J. A. (1998): Free radicals: Their history and current status in aging and disease. Ann. Clin. Lab. Sci. 28, 331-346

Leong X. F., Aishah U., Aini N., Das S., Jaarin K. (2008): Heated palm oil causes rise in blood pressure and cardiac changes in heart muscle in experimental rats. Arch. Med. Res. 39, 567-572 http://dx.doi.org/10.1016/j.arcmed.2008.04.009

Martin C. J., Goeddeke-Merickel C. M. (2005): Oxidative stress in chronic cardiovascular disease in chronic kidney disease from a cardiologist's perspective. Curr. Opin. Nephrol. Hypert. 13, 591-600

Moh M. H., Che Man Y. B., van de Voort F. R., Abdullah W. J. W. (1999): Determination of peroxide value in thermally oxidized crude palm oil by near infrared spectroscopy. JAOCS 76, 19-23 http://dx.doi.org/10.1007/s11746-999-0042-2

Mukherjee S., Mitra A. (2009): Health effects of palm oil. J. Hum. Ecol. 26, 197-203

Narang D., Sood S., Thomas M. K., Dinda A. K., Maulik S. K. (2004): Effect of dietary palm olein oil on oxidative stess associated with ischemic reperfusion injury in isolated rat heart. BMC Pharmacol. 4, 29 http://dx.doi.org/10.1186/1471-2210-4-29

Ng C-Y., Kamisah Y., Faizay O., Jubril Z., Qodriyah H. M. S., Jaarin K. (2012): Involvement of inflammation and adverse vascular remodelling in the blood pressure raising effect of repeatedly heated palm oil in Rats. Int. J. Vasc. Med. 2012, 404025 http://dx.doi.org/10.1155/2012/

Nowak G., Bakajsova D., Hayes C., Hauer-Jensen M., Compadre C. M. (2012): $\gamma$-Tocotrienol protects against mitochondrial dysfunction and renal cell death. J. Pharmacol. Exp. Ther. 340, 330-338 http://dx.doi.org/10.1124/jpet.111.186882

Odigie I. P., Ladipo C. O., Ettarh R. R., Izegbu M. C. (2004): Effect of chronic exposure to low levels of lead on renal function and ultrastructure in SD Rats. Niger. J. Physiol. Sci. 19, 27-32

Osim E. E., Owu D. U., Isong E. U., Umoh I. B. (1994): Influence of chronic consumption of thermoxidized and fresh palm oil 
diets on basal metabolic rate, body weight and morphology of tissues in rats. Discovery and Innovation 6, 389-396

Osim E. E., Owu D. U., Etta K. M. (1996): Arterial pressure and lipid profile in rats following chronic ingestion of palm oil diets. Afr. J. Med. Med. Sci. 25, 335-340

Owu D. U., Osim E. E., Ebong P. E. (1998): Serum liver enzymes profile of Wistar rats following chronic consumption of fresh or oxidized palm oil diets. Acta Trop. 69, 65-73 http://dx.doi.org/10.1016/S0001-706X(97)00115-0

Pfeffer M. A., McMurray J. J. V., Valazquez E. J., Rouleau J.-L., Kober L. Maggioni A. P. (2003): Vasartan, Captopril, or both in myocardial infarction complicated by heart failure, left ventricular dysfunction. N. Eng. J. Med. 349, 1893-1906

http://dx.doi.org/10.1056/NEJMoa032292

Rajavel V., Sattar M. Z. A., Abdullay M. A., Kassim N. M., Abdullah N. A. (2012): Chronic administration of oil palm (Elaeis guineensis) leaves extract attenuates hyperglycaemic-induced oxidative stress and improves renal histopathology and function in experimental diabetes. Evid. Based Complement Alternat. Med. 2012, 195367

http://dx.doi.org/10.1155/2012/195367
Samouilidou E. C., Graspa E. J., Kakavas I., Lagouranis A., Agrogiannis B. (2003): Oxidative stress markers and C-reactive protein in end stage renal failure patients on dialysis. Int. J. Urol. Nephrol. 35, 393-397 http://dx.doi.org/10.1023/B:UROL.0000022846.83505.3f

Schnackenberg C. G. (2002): Physiological and pathophysiological roles of oxygen radicals in the renal microvasculature. Am. J. Physiol. Reg. Integr. Comp. Physiol. 282, R335-342

Syed A. R., Adnan A., Qureshi F. A., Asim M. F., Najaf S. (2009): Analytical investigation of oxidative deterioration of sunflower oil stored under different conditions. EJEAFCHe 10, 1043-1051

Vaziri N. D. (2004): Roles of oxidative stress and antioxidant therapy in chronic kidney disease and hypertension. Curr. Opin. Nephrol. Hypert. 13, 93-99 http://dx.doi.org/10.1097/00041552-200401000-00013

World Health Organization (2003): Diet, nutrition and the prevention of Chronic Diseases. WHO Technical Report Series 916. Geneva 82, 88 and $88 \mathrm{c}$

Received: October 31, 2012

Final version accepted: September 10, 2013 